\title{
Cytokeratin and protein expression patterns in squamous cell carcinoma of the oral cavity provide evidence for two distinct pathogenetic pathways
}

\author{
GESCHE FROHWITTER ${ }^{1}$, HORST BUERGER ${ }^{1,2}$, PAUL J. VAN DIEST ${ }^{2}$, EBERHARD KORSCHING $^{3}$, \\ JOHANNES KLEINHEINZ ${ }^{4}$ and THOMAS FILLIES ${ }^{5}$
}

${ }_{1}^{1}$ Institute of Pathology, D-33098 Paderborn, Germany; ${ }^{2}$ Department of Pathology, University Medical Center Utrecht,
3584 CX Utrecht, The Netherlands; ${ }^{3}$ Institute of Bioinformatics, Faculty of Medicine, University of Münster;
${ }^{4}$ Department of Cranio and Maxillofacial Surgery, University Hospital Muenster, D-48149 Münster;
${ }^{5}$ Department of Cranio and Maxillofacial Surgery, Marienhospital Stuttgart, D-70199 Stuttgart, Germany

Received September 4, 2015; Accepted March 24, 2016

DOI: $10.3892 / \mathrm{ol} .2016 .4588$

\begin{abstract}
Squamous cell carcinoma (SCC) of the oral cavity is a morphological heterogeneous disease. Various cytokeratin (CK) expression patterns with different prognostic values have been described, but little is known concerning the underlying biological cell mechanisms. Therefore, the present study investigated 193 cases of oral SCCs using immunohistochemistry for $\alpha / \beta / \gamma$-catenin, glucose transporter 1 , caspase-3, X-linked inhibitor of apoptosis protein, hypoxia inducible factor- $1 \alpha$, carbonic anhydrase 9 , heat shock protein (hsp) 70, mast/stem cell growth factor receptor, p21, p27, p16, p53, B-cell lymphoma 6, epidermal growth factor receptor, cyclin D1 and CK1, 5/6, 8/18, 10, 14 and 19. Expression patterns were analyzed with biomathematical permutation analysis. The present results revealed a significant association between the expression of low-molecular weight CK8/18 and 19 and a high-tumor grade, $\beta$ and $\gamma$-catenin expression, deregulated cell cycle proteins and a predominant localization of the tumor on the floor of the mouth. By contrast, expression of high-molecular weight CK1, 5/6, 10 and 14 was significantly associated with the expression of p21 and hsp70. In conclusion, the current study presents evidence for the existence of two parallel pathogenetic pathways in oral SCCs, characterized by the expression of low- and high-molecular weight CKs. Additional studies are required to demonstrate the extent that these results may be used to improve therapeutic regimens.
\end{abstract}

\section{Introduction}

Squamous cell carcinoma (SCC) represents the vast majority $(90 \%)$ of malignant oral neoplasms (1). Recent figures on

Correspondence to: Mrs. Gesche Frohwitter, Institute of Pathology, 46a Husener Street, D-33098 Paderborn, Germany

E-mail: gesche.frohwitter@uni-muenster.de

Key words: squamous cell carcinoma, oral cavity, cytokeratins, tumor biology
SCCs emphasise the growing incidence rate and the limited and often unsatisfying treatment options $(2,3)$. Treatments are known to be unsatisfactory in terms of survival rates, as local and regional metastases occur frequently even in small tumors (4). The harm caused by agents, such as alcohol or tobacco, is important in cancerization, and may be responsible for the formation of secondary tumors and disease recurrence $(5,6)$. A detailed knowledge concerning the molecular mechanisms in the pathogenesis and progression of SCCs, and its precursor lesions, is required to aid in the improvement of therapeutics and incidence rates.

Cytokeratins (CKs) are major intermediate filaments in squamous epithelium and are critical in cell stabilization, shape, intracellular signalling and transport $(7,8)$. CK expression is a hallmark of tumor progression. Previous studies demonstrated that the expression of high-molecular weight CK8 and 18 was associated with dysplasia grades of tumor precursor lesions and an unfavorable prognosis for patients with SCCs $(9,10)$. Other studies had similar observations $(11,12)$. Loss of CK8 phosphorylation initiates an increased cell migration and tumor spread in SCCs, whereas loss of CK8 and 18 led to alterations in $\alpha 6 \beta 4$-integrin mediated signalling and decreased neoplastic progression $(11,13,14)$. In addition, an increased expression of low-molecular weight CK19 was associated with high-grade dysplasia and squamous intraepithelial neoplasia and a decreased survival rate of patients with SCCs $(9,15)$. CK19 expression is not observed in benign or hyperplastic regions of keratinized oral epithelium $(10,15)$. Additionally, the expression of CKs interferes with a multitude of other intracellular regulation pathways, including numerous kinases, receptors and apoptotic proteins (16); therefore, the effects of CKs are highly complex.

The present study demonstrates the frequencies of low and high molecular weight CKs in SCCs of the oral cavity with respect to their anatomical sublocalization, and evaluates the coexpression of a multitude of proteins involved in various cellular regulatory pathways. The aim of the present study was to elucidate the complex interaction between CK expression patterns and alterations in other cellular pathways. The present 
results revealed the existence of two pathogenetic pathways in the evolution of oral SCC, which are associated with the preferential expression of low- and high-molecular weight CKs.

\section{Patients and methods}

Patients. All patients eligible for the current study presented with histologically confirmed oral SCC, and underwent surgery at the University Hospital Muenster (Münster, Germany) between January 1988 and December 2000. Data collection and evaluation was conducted in compliance with the current version of the Declaration of Helsinki and the International Conference for Harmonization of Good Clinical Practice $(17,18)$. All data and specimens were evaluated after obtaining written informed consent from the patient and ethical approval from the Ethical Commission of the Medical Association Westfalen-Lippe and the Faculty of Medicine of the Westphalian Wilhelms-University Muenster. The tumor samples were formalin-fixed, archival paraffin-embedded tissues from 193 patients (154 men; 39 women) with primary oral SCC. The patients' mean age was 59 years (range, 31-90 years) (Table I). Information regarding clinicopathological details and treatment modalities of this tumor series is described in previous studies $(9,10,19-21)$. According to the Union for International Cancer Control guidelines (22), all the SCCs were classified post-surgery by the tumor-node-metastasis system $(\mathrm{T} 1=96, \mathrm{~T} 2=82, \mathrm{~T} 3-4=15 ; \mathrm{N} 0=136, \mathrm{~N}>0=57)$. All patients attended a follow-up program with clinical evaluation for 4-181 months. As described in previous studies $(9,10,19-21)$, the time of survival was defined as the time between the date of surgery and the date of histopathologically proven tumor recurrence, metastatic disease, death associated with the disease or a tumor-free follow-up period of 60 months. Patients who missed regular attendance at follow-up were excluded from the present study.

Immunohistochemistry. To provide equal assessment conditions, all tumor samples were analyzed by tissue microarray (TMA) and immunohistochemistry. As previously described (23), all TMAs were used according to a standard procedure. For the TMA block construction, two punch biopsies (diameter, $0.6 \mathrm{~mm}$ ) were extracted from formalin-fixed, paraffin-embedded tumor tissue (thickness, $4 \mu \mathrm{m}$ ) using a tissue microarray instrument (Beecher Instruments, Inc., Sun Prairie, WI, USA) and inserted into a novel acceptor block. The acceptor block underwent deparaffinization, using various concentrations of ethanol (70, 95 and 100\%; Walter-CMP GmbH \& Co. KG, Kiel, Germany) and rehydration. Endogenous peroxidase activity was blocked using methanol (with $0.3 \%$ hydrogen peroxide) (Walter-CMP GmbH \& Co. KG) for $30 \mathrm{~min}$. Antigen retrieval was preceded by a cooling time of $20 \mathrm{~min}$ at room temperature and incubation with primary antibodies for $30 \mathrm{~min}$ at room temperature (Table II). Catalyzed Signal Amplification System (Dako, Glostrup, Denmark) was used for CK1, 5/6, 8/18, 10, 14 and 19 immunohistochemistry, according to the manufacturer's protocol. The staining procedures for $\mathrm{p} 53, \mathrm{p} 21, \mathrm{p} 27$, p16, cyclin D1, epidermal growth factor receptor, mast/stem cell growth factor receptor (c-kit), B-cell lymphoma $6, \alpha / \beta / \gamma$-catenin, hypoxia inducible factor-1 $\alpha$ (HIF-1 $\alpha$ ), glucose transporter 1 (GLUT1), carbonic
Table I. Clinicopathological characteristics of 193 patients with oral squamous cell carcinoma.

\begin{tabular}{lr} 
Characteristic & Value \\
\hline Age at diagnosis, years & \\
Mean & 59 \\
Range & $31-90$ \\
Gender & \\
Female & 39 \\
Male & 154 \\
Tumor stage & \\
T1 & 96 \\
T2 & 82 \\
T3-T4 & 15
\end{tabular}

Lymph node

Negative 136

Positive $\quad 57$

Tumor grade

G1 44

G2 126

G3 23

Disease recurrence

Positive 66

Negative 127

Localization

Floor of mouth $\quad 76$

Tongue $\quad 49$

Other $\quad 68$

anhydrase 9 (CAIX), caspase-3, heat shock protein (hsp) 70 and X-linked inhibitor of apoptosis protein (XIAP) were performed as previously described $(24,25)$. Antigen detection was performed by a standardised avidin-biotin complex method using anti-rabbit and anti-mouse biotinylated antibodies [Dako REAL Detection Systems (LSAB+); catalog no. K5003; Dako] and a Biotin-Blocking System (Ready-to-Use, catalog no. X0590; Dako). Diaminobenzidine (included in the p16 and EGFR kits; Table II) or LSAB 2 System-AP (Dako) was used for visualization, along with counterstaining with hematoxylin for $45 \mathrm{sec}$, followed by dehydration in alcohol and xylene (Walter-CMP GmbH \& Co. KG). During TMA analysis and immunohistochemistry, negative (omission of the primary antibody) and positive controls were performed.

Scoring of staining. Expression of CK1, 5/6, 8/18, 10, 14 and 19 was evaluated by the rate of positively stained cells in each core. The expression levels (\%) were classified into three groups for CK19 (0\%, no expression; $1-50 \%$, moderate expression; $>50 \%$, high expression) and into two groups for CK5/6, 8/18, 1, 10 and 14 ( $0 \%$, no expression; $\geq 1 \%$, positive expression). The mean percentage value of two cores from one tumor was calculated. Cytoplasmic expression of hsp70, caspase-3 and XIAP was graded as negative or positive (intermediate to strong expression), irrespective of the relative number of stained tumor cells. 
Table II. Primary antibodies used for immunohistochemistry in the present study.

\begin{tabular}{|c|c|c|c|c|c|c|c|}
\hline Antibody & Supplier & Catalog no. & Clone & $\begin{array}{c}\text { Mono/ } \\
\text { polyclonal }\end{array}$ & Species & Dilution & Antigen retrieval \\
\hline p21 & Merck Millipore & $05-655$ & CP74 & Mono & Mouse & $1: 500$ & Citrate buffer (pH6) \\
\hline p27 & BD TL & 610241 & 57/Kip1/p27 & Mono & Mouse & $1: 1,000$ & Citrate buffer (pH6) \\
\hline p53 & Dako & M7001 & DO-7 & Mono & Mouse & $1: 100$ & EDTA (pH8) \\
\hline $\mathrm{HIF}-1 \alpha$ & BD TL & 610958 & $54 / \mathrm{HIF}-1 \alpha$ & Mono & Mouse & $1: 50$ & EDTA (pH8) \\
\hline GLUT1 & Dako & M7211 & Clone A 35 & Mono & Mouse & $1: 40$ & EDTA (pH8) \\
\hline CAIX & Abcam & ab128883 & - & Poly & Rabbit & $1: 1,000$ & Citrate buffer (pH6) \\
\hline XIAP & BD TL & 610716 & 28/hILP/XIAP & Mono & Mouse & $1: 50$ & Citrate buffer (pH6) \\
\hline Hsp 70 & Invitrogen & $33-3800$ & MB-H1 & Mono & Mouse & $1: 40$ & Citrate buffer (pH6) \\
\hline$\alpha$-catenin & BD TL & 610194 & 5/a-catenin & Mono & Mouse & $1: 250$ & EDTA (pH8) \\
\hline$\beta$-catenin & BD TL & 610153 & 14/beta-Catenin & Mono & Mouse & $1: 1,000$ & EDTA (pH8) \\
\hline$\gamma$-catenin & BD TL & 610253 & $15 / \gamma$-catenin & Mono & Mouse & $1: 1,500$ & EDTA (pH8) \\
\hline BCL-6 & Dako & M7211 & PG-B6p & Mono & Mouse & $1: 50$ & Citrate buffer (pH6) \\
\hline Caspase-3 & Invitrogen & $35-1600 Z$ & 43191 & Mono & Mouse & $1: 100$ & Citrate buffer (pH6) \\
\hline C-kit & Dako & A4502 & - & Poly & Rabbit & $1: 200$ & Citrate buffer (pH6) \\
\hline CK1 & Novocastra & NCL-Ck1 & $34 \beta \mathrm{B} 4$ & Mono & Mouse & $1: 150$ & Citrate buffer (pH6) \\
\hline CK5/6 & Dako & M7237 & D5/16 B4 & Mono & Mouse & $1: 80$ & Autoclave (10 min) \\
\hline CK10 & Dako & M7002 & DE-K10 & Mono & Mouse & $1: 400$ & Citrate buffer (pH6) \\
\hline CK14 & Dianova GmbH & DLN-06600 & LL002 & Mono & Mouse & $1: 50$ & Citrate buffer (pH6) \\
\hline CK8/18 & Dianova GmbH & DLN-08110 & K8.8/DC10 & Mono & Mouse & $1: 40$ & $\begin{array}{l}\text { Autoclave }(10 \mathrm{~min}) \text {, } \\
\text { citrate buffer }(\mathrm{pH})\end{array}$ \\
\hline CK19 & Dianova GmbH & DLN-08330 & KS19.1 & Mono & Mouse & $1: 80$ & Citrate buffer (pH6) \\
\hline Cyclin D1 & Novocastra & $\begin{array}{l}\text { NCL-L-cyclin } \\
\text { D1-GM }\end{array}$ & P2D11F11 & Mono & Mouse & $1: 20$ & EDTA (pH8) \\
\hline EGFR & Dako & K1492 & pharmDX kit & Mono & Mouse & - & - \\
\hline p16 & CINtec & 9517 & E6H4 & Mono & Mouse & & Citrate buffer (pH6) \\
\hline
\end{tabular}

Merck Millipore, Darmstadt, Germany; BD TL, BD Transduction Laboratories ${ }^{\text {TM }}$, BD Biosciences, Frankling Lakes, NJ, USA; Dako, Glostrup, Denmark; Invitrogen ${ }^{\mathrm{TM}}$, Thermo Fisher Scientific, Inc., Waltham, MA, USA; Abcam, Cambridge, UK; Novocastra ${ }^{\mathrm{TM}}$, Leica Biosystems $\mathrm{GmbH}$, Nussloch, Germany; Dianova GmbH, Hamburg, Germany; CINtec ${ }^{\circledR}$, Roche AG, Basel Switzerland. EDTA and citrate buffers were purchased from Dako and Zytomed Systems GmbH (Berlin, Germany), respectively. CK, cytokeratin; HIF-1 $\alpha$, hypoxia inducible factor-1 $\alpha$; GLUT1, glucose transporter 1; XIAP, X-linked inhibitor of apoptosis protein; CAIX, carbonic anhydrase 9; Hsp, heat shock protein; C-kit, mast/stem cell growth factor receptor; BCL-6, B-cell lymphoma-6; EGFR, epidermal growth factor receptor.
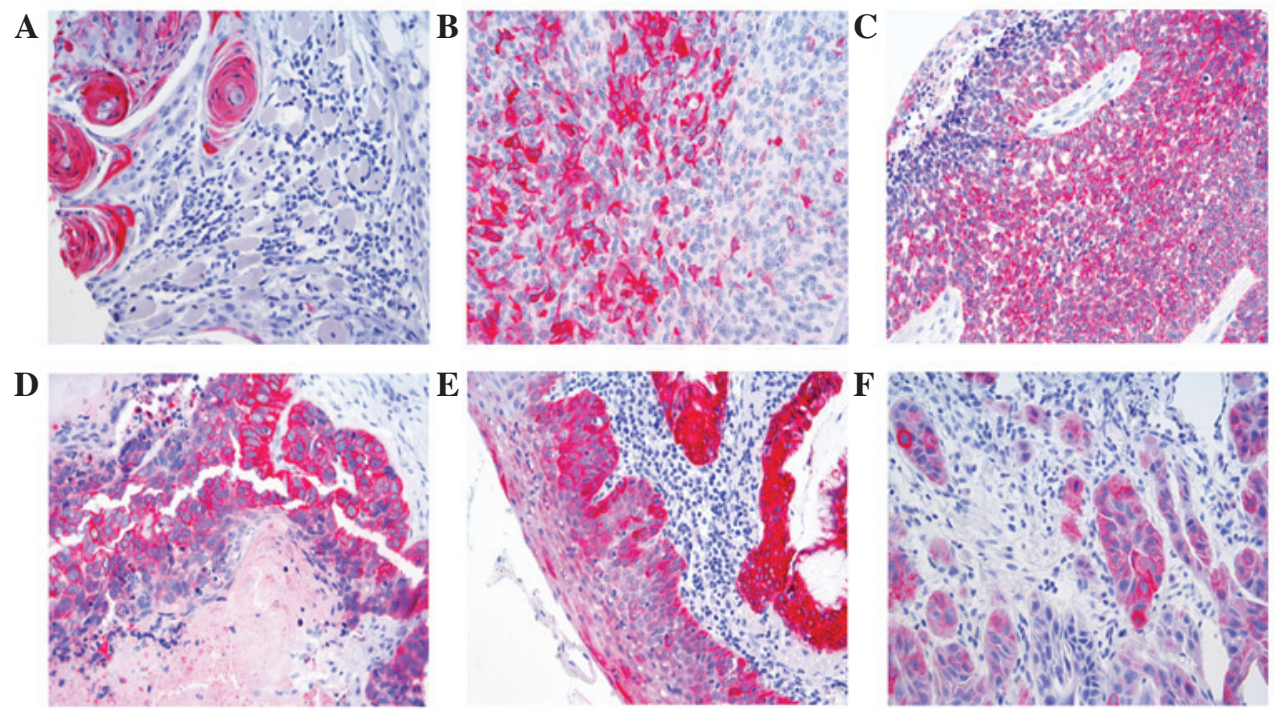

Figure 1. Representative samples of positive immunohistochemical staining with CK antibodies in oral squamous cell carcinoma. (A and B) CK10, (C and D) CK8/18 and (E and F) CK19 (magnification, x10). CK, cytokeratin. 
The remaning molcecules were assessed as follows: CAIX and $\mathrm{p} 21 / 27 / 16$ ( $<1 \%$, no expression; $\geq 1 \%$, positive expression); HIF- $1 \alpha$ and GLUT1 $(<1 \%$, no expression; $\geq 1-4 \%$, low expression; $\geq 5 \%$, high expression); BCL- $6, \alpha$-catenin, cyclin D1, c-kit and EGFR (0-15\%, no expression; 16-50\%, low expression; $85-100 \%$, positive expression); $\beta / \gamma$-catenin $(0-15 \%$, no expression; $16-50 \%$, low expression; $51-100 \%$, high expression); p53 ( $<5 \%$, no expression; $\geq 5-50 \%$, low expression; $\geq 50 \%$, high expression). Moderate, intermediate, strong and high expressions were rendered as positive expression.

Statistical analysis. Statistical analysis was performed using $\chi^{2}$ analysis. Biomathematical analysis of immunohistochemical data was evaluated using permutation analysis, which analyses information from protein-expression patterns of TMA data and identifies synergistic or antagonistic effects amongst all evaluated proteins (26). Botstein et al (27) describe this method as preserving the original physiological information of the tumor tissue and revealing the different compounds of the tumor samples to the smallest detail $(28,29)$. This combinatorial analysis calculates the ideal precedence of protein-expression coherence; therefore allowing the generation of an overview of differential regulation patterns in different tumor subgroups. A detailed description of this approach and its use in a clinical setting, using TMA data, have been previously described $(24,29)$. Statistical analysis was performed on $\mathrm{R}$ version 3.1.3 software (www.r-project. org/), Fortran 95-based program 'TMAinspiration' (complex-systems.uni-muenster.de/tma_inspiration.html) and SPSS version 21.0 software (IBM SPSS, Armonk, NY, USA)

\section{Results}

CK expression patterns and tumor localization. The expression (\%) of the $6 \mathrm{CKs}$ and other biomarkers in the SCC tumors are presented in Table III. Representative images of immunohistochemical staining are presented in Fig. 1.

Global, but not individual, CK expression in oral SCCs was significantly different between the anatomical localization of the tumor in the floor of the mouth and other localizations (floor of mouth vs. tongue, $\mathrm{P}=1.6 \times 10^{-4}$; floor of mouth vs. other localizations, $\mathrm{P}=1.3 \times 10^{-4}$; Fig. $2 \mathrm{~A}$ ). SCCs located on the floor of the mouth revealed inverse regression lines in contrast to SCCs of other tumor subsites within the oral cavity, including the maxilla, tonsils and buccal region. Expression of CK8/18 and 19 was associated with SCCs of the floor of the mouth, whereas CK1, 10, 8/18 and 19 were equally expressed in all other subsites (Fig. 2A).

CK expression patterns and tumor grade. Significant differences could be observed in global CK expression patterns in association with tumor grade. Regression lines for grade 2 (G2) and 3 (G3) SCCs were similar, but regression lines for grade 1 (G1) SCCs exhibited an inverse behavior compared to G2 and G3 (Fig. 2B).

G1 carcinomas revealed a statistically significant inverse association with $\mathrm{G} 2$ and $\mathrm{G} 3$ carcinomas concerning the expression of $\mathrm{CK} 19\left(\mathrm{P}=4.1 \times 10^{-5}\right.$ and $\mathrm{P}=6.9 \times 10^{-5}$, respectively). Expression of CK14 and 1 was predominantly observed in G3 SCCs $\left(\mathrm{P}=5.1 \times 10^{-3}\right.$ and $\mathrm{P}=0.03$, respectively).
Table III. Expression of CKs and other biomarkers in 193 samples of oral squamous cell carcinoma.

\begin{tabular}{lrr}
\hline & \multicolumn{2}{c}{ Expression, \% of tumors } \\
\cline { 2 - 3 } Protein & Negative & Positive \\
\hline CK1 & 53.9 & 0.5 \\
CK5/6 & 1.7 & 98.3 \\
CK8/18 & 33.3 & 66.7 \\
CK10 & 62.8 & 37.2 \\
CK14 & 2.6 & 97.4 \\
CK19 & 59.9 & 40.1 \\
$\alpha$-catenin & 34.6 & 65.4 \\
$\beta$-catenin & 15.8 & 84.2 \\
$\gamma$-catenin & 35.0 & 65.0 \\
GLUT1 & 8.5 & 91.5 \\
Caspase-3 & 74.2 & 25.8 \\
XIAP & 80.5 & 19.5 \\
CAIX & 73.4 & 26.6 \\
Hsp 70 & 89.3 & 10.7 \\
C-kit & 86.4 & 13.6 \\
p16 & 79.4 & 20.6 \\
p21 & 28.8 & 71.2 \\
p27 & 79.8 & 20.2 \\
p53 & 0.0 & 100.0 \\
BCL-6 & 78.7 & 21.3 \\
EGFR & 24.9 & 75.1 \\
Cyclin D1 & 50.6 & 49.4 \\
HIF-1 $\alpha$ & 42.2 & 57.8 \\
\hline CK & & \\
\hline
\end{tabular}

CK, cytokeratin; GLUT1, glucose transporter 1; XIAP, X-linked inhibitor of apoptosis protein; CAIX, carbonic anhydrase 9; Hsp, heat shock protein; C-kit, mast/stem cell growth factor receptor; BCL-6, B-cell lymphoma-6; EGFR, epidermal growth factor receptor; HIF-1 $\alpha$, hypoxia inducible factor- $1 \alpha$.

CK expression patterns and cell cycle proteins and growth factors. Two patterns of cell cycle proteins expression were observed in association with CK expression. High-molecular weight CK14, 5/6, 1 and 10 exhibited similar regression lines compared with the regression lines exhibited by low-molecular weight $\mathrm{CK} 8 / 18$ and 19. In this molecular pattern $\mathrm{p} 21$, due to its extreme position in the regression approach, has the strongest impact in discriminating between the 6 CKs (Fig. 2C). By contrast, EGFR does not play a major regulative role.

CK expression patterns and factors involved in cell motility, apoptosis and cellular stress responses. Similar findings were observed in a second approach for factors involved in cell motility, apoptosis and cellular stress responses. As demonstrated in Fig. 2C, CK14, 5/6, 1 and 10 revealed a contrasting expression compared with CK8/18 and 19. Comparable results were observed for $\mathrm{c}$-kit, $\alpha / \beta / \gamma$-catenin, HIF- $1 \alpha$, GLUT1, CAIX, caspase-3, hsp 70 and XIAP (Fig. 2D). In this second pattern, the discriminating role was primarily performed by $\gamma$-catenin and hsp 70. 
A

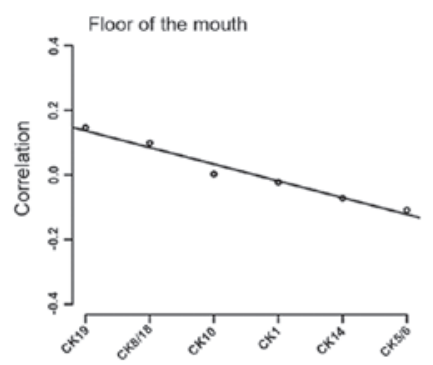

B

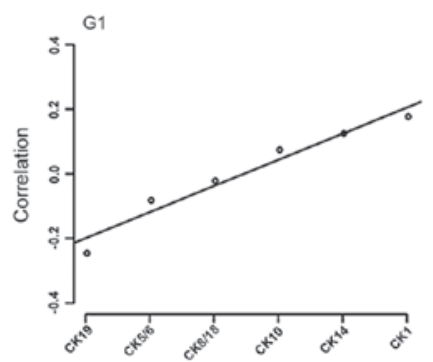

C
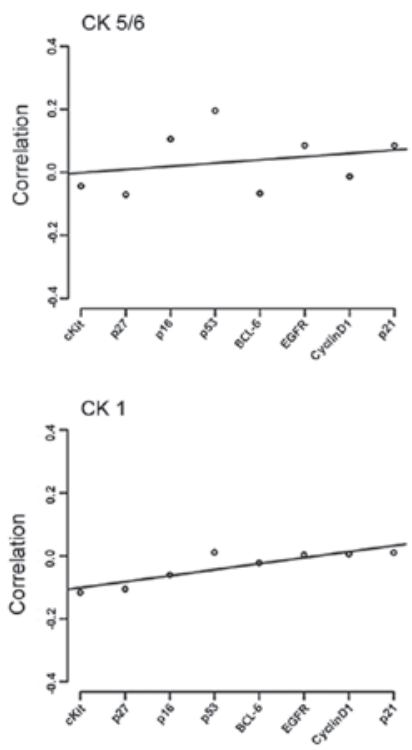

D

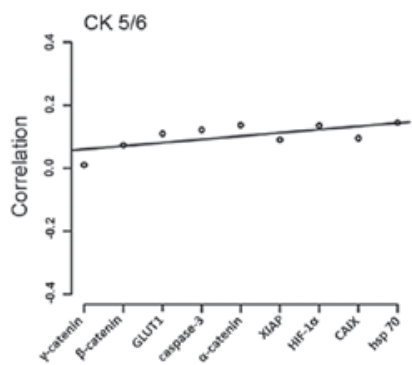

CK 1

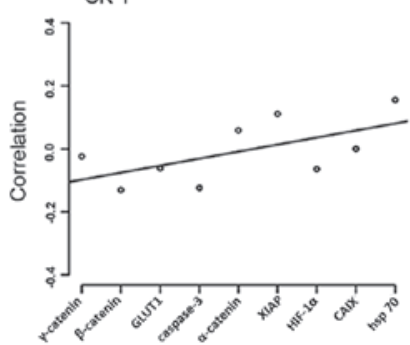

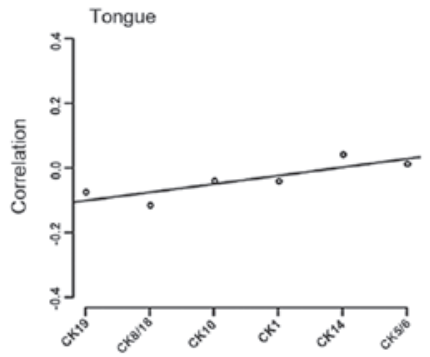
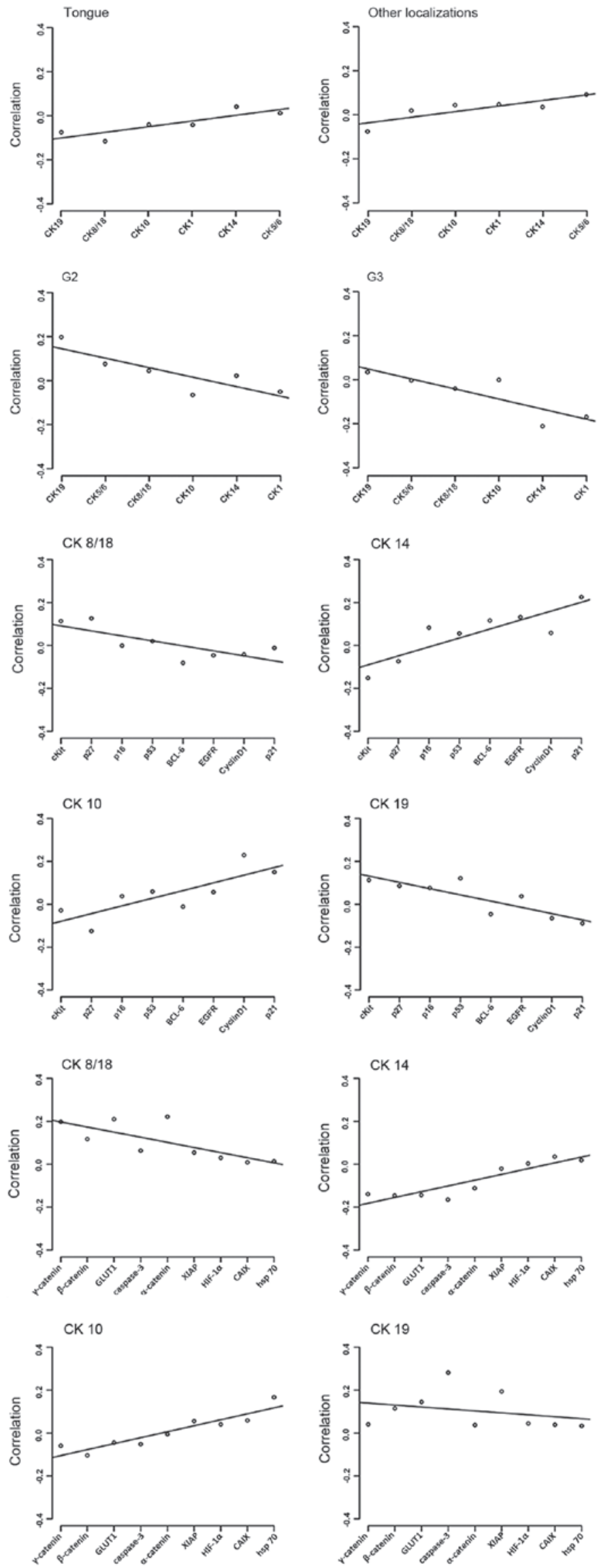

Figure 2. Regression curves of the evaluated tumor samples examined by permutation analysis. (A) Oral tumor samples analyzed according to their localization and CK expression profile. (B) Tumor samples analyzed according to their histopathological grading and CK expression profile. (C) CK expression analyzed according to cell cycle and growth control regulation proteins. (D) CK expression analyzed according to hypoxic stress and cellular adhesion proteins. CK, cytokeratin; HIF-1 $\alpha$, hypoxia inducible factor-1 $\alpha$; GLUT1, glucose transporter 1; XIAP, X-linked inhibitor of apoptosis protein; CAIX, carbonic anhydrase 9; Hsp, heat shock protein; C-kit, mast/stem cell growth factor receptor; BCL-6, B-cell lymphoma-6; EGFR, epidermal growth factor receptor. 


\section{Discussion}

SCC of the oral cavity is associated with a variety of risk factors, including smoking, alcohol abuse, tobacco chewing, oral hygiene and human papilloma virus (HPV) infection (30-34). The current treatment protocols are based on a combination of surgery and radio/chemotherapy $(35,36)$. Despite these complex, multidisciplinary treatment regimens, the long term results are unsatisfactory $(1,37)$, the reasons for which are unclear. The underlying biology of SCCs remains poorly understood, and discerning the distinct molecular mechanisms underlying SCC may lead to improvements in treatment strategies.

CKs are the major intermediate filaments of squamous epithelium $(38,39)$, and in different organ systems it has been demonstrated that alterations in CK expression patterns leads to the altered expression of numerous genes and proteins $(9-11,40)$.

The present study demonstrates that previously described $(9,10)$ prognostically relevant cytokeratin expression patterns are associated with different expression patterns of crucial cellular proteins. Low-molecular weight CK8/18 and 19 expression had opposing patterns to high-molecular weight CK1,5/6, 10 and 14 with biomarkers involving cell cycle regulation (p21), hypoxic stress (HIF-1 $\alpha$ and CAIX) or cellular adhesion ( $\alpha / \gamma$-catenin). This indicates that $\mathrm{CK} 8 / 18$ and 19 are expressed in poorly-differentiated hypoxic SCC with a higher degree of cell cycle deregulation, whereas CK1, 5/6, 10 and 14 appear to be expressed in well-differentiated cancers with lower hypoxia and cell cycle deregulation. These results are similar to the general observation that low-molecular weight CK8/18 and 19 cytokeratins, whose expression is a hallmark of glandular tissues, are not physiologically expressed in normal squamous epithelium, but may be expressed during carcinogenesis $(11,12,41)$.

These results are similar to previous studies regarding the prognostic significance of these proteins $(9,10,19,21)$. However, the interpretation of these findings is challenging, since it cannot be excluded that these alterations in expression of CKs and the chosen biomarkers are a reflection of tumor progression. By contrast, the present results may allow an alternative interpretation; in invasive breast cancer it was previously demonstrated that the expression of distinct high-molecular weight CKs defines a subgroup of poorly-differentiated breast cancer, representing a unique, independent pathway associated with poor prognosis, which has different responses to various treatment modalities $(42,43)$. Therefore, the present results may be as a result of the existence of different pathways in the pathogenesis of oral SCCs. At present, two pathways characterized by the differential expression of CKs may be distinguished in the present study. In various other tumor entities, such parallel, independent pathogenetic pathways have been reported for colorectal cancer, ovarian cancer and SCCs of the female genital tract, including the vulva and cervix (24,44-46).

In addition, the present authors consider that the results support the hypothesis that SCCs of the oral cavity may not be regarded as a homogeneous entity. In the present study, global expression patterns of high- and low-molecular weight CKs exhibit clear differences between G1 and G2/3 SCCs. It may be argued that the alteration in $\mathrm{CK}$ expression has been interpreted as a result of tumor dedifferentiation. However, the present authors hypothesize that this may not be true for several reasons. The expression of CK8/18 and 19 has been described in epithelial precursor lesions of oral SCC (10), and therefore does not support the hypothesis that CK8/18 and 19 expression is a late phenomena in carcinogenesis after invasion has occurred. It is also widely accepted that CK expression patterns appear to be highly conserved during tumor progression (8). As a consequence, the existence of CK8/18 and/or 19-positive oral SCC raises fundamental controversies concerning their formal pathogenesis $(9,10,12,41)$. These carcinomas appear to represent an independent pathway rather than being the endstage of a stepwise dedifferentiation of CK8/18/19 negative SCCs. Therefore, it may be postulated that there is a low- and high-grade pathway. A similar concept has also been proposed for squamous intraepithelial neoplasms in the cervix and the vulva $(47,48)$, which is associated with various HPV subtypes (44).

The oral cavity is a highly complex anatomical region, emerging from various branchial arches that are associated with an aggregation of mesenchyme, ectoderm and endoderm (49-51); however, to what extent tumor localization has an effect on tumor biology and prognosis remains to be demonstrated. The present results reveal that differences appear to exist between SCCs on the floor of the mouth and SCCs of other anatomical subsites within the oral cavity, as observed by previous studies $(5,21,52,53)$. In the present study, SCCs of the floor of the mouth had an increased expressed of CK8/18 and 19. The number of tumors investigated in the present study was too small to allow for a definite conclusion; however the present results reveal that complex interactions appear to exist between the expression of CKs and other major cellular proteins, as well as tumor grade and anatomical sublocalization of SCCs of the oral cavity.

In summary, the present study analyzed low- and high-molecular weight $\mathrm{CK}$ expression in association with the expression of various other major cellular proteins using a sophisticated biomathematical algorithm in a series of 193 SCCs of the oral cavity. The present study provided evidence of the existence of two pathogenetic pathways characterized by the expression of low- and high-molecular weight CKs in oral SCC. These results provide evidence for additional investigation concerning the pathways identified and provide improved understanding of oral tumor biology.

\section{References}

1. Scully C and Bagan J: Oral squamous cell carcinoma overview. Oral Oncol 45: 301-308, 2009.

2. American Cancer Society: Cancer Facts \& Figures 2015. American Cancer Society, Altanta, GA, 2015.

3. Cancer Research UK: Oral cancer incidence statistics.http://www. cancerresearchuk.org/health-professional/cancer-statistics/statisticsby-cancer-type/oral-cancer/incidence.s

4. D'Cruz AK, Vaish R, Kapre N, Dandekar M, Gupta S, Hawaldar R, Agarwal JP, Pantvaidya G, Chaukar D, Deshmukh A, et al; Head and Neck Disease Management Group: Elective versus therapeutic neck dissection in node-negative oral cancer. N Engl J Med 373: 521-529, 2015.

5. Yamauchi K, Fujioka Y, Kogashiwa Y and Kohno N: Quantitative expression study of four cytokeratins and p63 in squamous cell carcinoma of the tongue: Suitability for sentinel node navigation surgery using one-step nucleic acid amplification. J Clin Pathol 64: 875-879, 2011. 
6. Slaughter DP, Southwick HW and Smejkal W: Field cancerization in oral stratified squamous epithelium; clinical implications of multicentric origin. Cancer 6: 963-968, 1953.

7. Chu PG and Weiss LM: Keratin expression in human tissues and neoplasms. Histopathology 40: 403-439, 2002.

8. Moll R, Franke WW, Schiller DL, Geiger B and Krepler R: The catalog of human cytokeratins: Patterns of expression in normal epithelia, tumors and cultured cells. Cell 31: 11-24, 1982.

9. Fillies T, Werkmeister R, Packeisen J, Brandt B, Morin P, Weingart D, Joos U and Buerger H: Cytokeratin 8/18 expression indicates a poor prognosis in squamous cell carcinomas of the oral cavity. BMC Cancer 6: 10, 2006.

10. Fillies T, Jogschies M,Kleinheinz J, Brandt B, Joos U and Buerger H: Cytokeratin alteration in oral leukoplakia and oral squamous cel carcinoma. Oncol Rep 18: 639-643, 2007.

11. Alam H, Gangadaran P,Bhate AV, ChaukarDA, Sawant SS, Tiwari R, Bobade J, Kannan S, D'Cruz AK, Kane S and Vaidya MM: Loss of keratin 8 phosphorylation leads to increased tumor progression and correlates with clinico-pathological parameters of OSCC patients. PLoS One 6: e27767, 2011.

12. Gires O, Mack B, Rauch J and Matthias C: CK8 correlates with malignancy in leukoplakia and carcinomas of the head and neck Biochem Biophys Res Commun 343: 252-259, 2006.

13. Raul U, Sawant S, Dange P, Kalraiya R, Ingle A and Vaidya M: Implications of cytokeratin 8/18 filament formation in stratified epithelial cells: Induction of transformed phenotype. Int J Cancer 111: 662-668, 2004

14. Alam H, Kundu ST, Dalal SN and Vaidya MM: Loss of keratins 8 and 18 leads to alterations in $\alpha 6 \beta 4$-integrin-mediated signalling and decreased neoplastic progression in an oral-tumour-derived cell line. J Cell Sci 124: 2096-2106, 2011.

15. Lindberg K and Rheinwald JG: Suprabasal 40 kd keratin (K19) expression as an immunohistologic marker of premalignancy in oral epithelium. Am J Pathol 134: 89-98, 1989.

16. Paramio JM and Jorcano JL: Beyond structure: Do intermediate filaments modulate cell signalling? Bioessays 24: 836-844, 2002.

17. World Medical Association: World Medical Association Declaration of Helsinki. Ethical principles for medical research involving human subjects. Bull World Health Organ 79: 373-374, 2001.

18. Barton A: Handbook for good clinical research practice (GCP) Guidance forsimplementation. J Epidemiol Community Health 61: $559,2007$.

19. Fillies T, Woltering M, Brandt B, Van Diest JP, Werkmeister R, Joos $\mathrm{U}$ and Buerger $\mathrm{H}$ : Cell cycle regulating proteins $\mathrm{p} 21$ and $\mathrm{p} 27$ in prognosis of oral squamous cell carcinomas. Oncol Rep 17: 355-359, 2007.

20. Fillies T, Werkmeister R, van Diest PJ, Brandt B, Joos U and Buerger H: HIF1-alpha overexpression indicates a good prognosis in early stage squamous cell carcinomas of the oral floor. BMC Cancer 5: 84, 2005

21. Fillies T, Buerger H, Gaertner C, August C, Brandt B, Joos U and Werkmeister R: Catenin expression in T1/2 carcinomas of the floor of the mouth. Int J Oral Maxillofac Surg 34: 907-911, 2005.

22. Sobin LH, Gospodarowicz MK and Wittekind C (eds): UICC TNM Classification of Malignant Tumours, 7th Edition. Wiley-Blackwell, Hoboken, NJ, 2009.

23. Packeisen J, Buerger H, Krech R and Boecker W: Tissue microarrays: A new approach for quality control in immunohistochemistry. J Clin Pathol 55: 613-615, 2002

24. Schymik B, Buerger H, Krämer A, Voss U, van der Groep P, Meinerz W, van Diest PJ and Korsching E: Is there 'progression through grade' in ductal invasive breast cancer? Breast Cancer Res Treat 135: 693-703, 2012

25. Helms MW, Packeisen J, August C, Schittek B, Boecker W, Brandt $\mathrm{BH}$ and Buerger $\mathrm{H}$ : First evidence supporting a potential role for the BMP/SMAD pathway in the progression of oestrogen receptor-positive breast cancer. J Pathol 206: 366-376, 2005.

26. Packeisen J, Korsching E, Herbst H, Boecker W and Buerger H: Demystified...tissue microarray technology. Mol Pathol 56: 198-204, 2003.

27. Botstein D and Fink GR: Yeast: An experimental organism for 21st Century biology. Genetics 189: 695-704, 2011.

28. Vidal M, Cusick ME and Barabási AL: Interactome networks and human disease. Cell 144: 986-998, 2011.

29. Buerger H, Boecker F, Packeisen J, Agelopoulos K, Poos K, Nadler W and Korsching E: Analyzing the basic principles of tissue microarray data measuring the cooperative phenomena of marker proteins in invasive breast cancer. Open Access Bioinformatics 5: 1-21, 2013.

30. Warnakulasuriya S: Global epidemiology of oral and oropharyngeal cancer. Oral Oncol 45: 309-316, 2009
31. Petti S: Lifestyle risk factors for oral cancer. Oral Oncol 45: 340-350, 2009.

32. Moergel M, Kammerer P, Kasaj A, Armouti E, Alshihri A, Weyer V and Al-Nawas B: Chronic periodontitis and its possible association with oral squamous cell carcinoma - a retrospective case control study. Head Face Med 9: 39, 2013

33. Feller L, Wood NH, Khammissa RA and Lemmer J: Human papillomavirus-mediated carcinogenesis and HPV-associated oral and oropharyngeal squamous cell carcinoma. Part 1: Human papillomavirus-mediated carcinogenesis. Head Face Med 6: 14, 2010

34. Feller L, Wood NH, Khammissa RA and Lemmer J: Human papillomavirus-mediated carcinogenesis and HPV-associated oral and oropharyngeal squamous cell carcinoma. Part 2: Human papillomavirus associated oral and oropharyngeal squamous cell carcinoma. Head Face Med 6: 15, 2010.

35. AWMF and GAOOAM: Surgery Guidelines for Oncology, S3: Guideline for diagnostics and treatment of oral cancer. AWMF-Register-Number (007-100O, 2012L): 119, 2012 (In German).

36. Frerich B: Standard therapy of oral squamous epithelial carcinoma. Onkologe 16: 527-536, 2010 (In German).

37. Institut RK and GEKID: Cancer in Germany 2007/2008. Journal 137, 2012 (In German).

38. Steinert PM, Idler WW and Zimmerman SB: Self-assembly of bovine epidermal keratin filaments in vitro. J Mol Biol 108: 547-567, 1976

39. Romano V, Bosco P, Rocchi M, Costa G, Leube RE, Franke WW and Romeo G: Chromosomal assignments of human type I and type II cytokeratin genes to different chromosomes. Cytogenet Cell Genet 48: 148-151, 1988.

40. Thiel UJ, Feltens R, Adryan B, Gieringer R, Brochhausen C, Schuon R, Fillies T, Grus F, Mann WJ and Brieger J: Analysis of differentially expressed proteins in oral squamous cell carcinoma by MALDI-TOF MS. J Oral Pathol Med 40: 369-379, 2011

41. Zhong LP, Chen WT, Zhang CP and Zhang ZY: Increased CK19 expression correlated with pathologic differentiation grade and prognosis in oral squamous cell carcinoma patients. Oral Surg Oral Med Oral Pathol Oral Radiol Endod 104: 377-384, 2007.

42. Korsching E, Packeisen J, Agelopoulos K, Eisenacher M, Voss R, Isola J, van Diest PJ, Brandt B, Boecker W and Buerger H: Cytogenetic alterations and cytokeratin expression patterns in breast cancer: Integrating a new model of breast differentiation into cytogenetic pathways of breast carcinogenesis. Lab Invest 82: $1525-1533,2002$

43. Korsching E, Jeffrey SS, Meinerz W, Decker T, Boecker W and Buerger H: Basal carcinoma of the breast revisited: An old entity with new interpretations. J Clin Pathol 61: 553-560, 2008.

44. Schiffman M, Castle PE, Jeronimo J, Rodriguez AC and Wacholder S: Human papillomavirus and cervical cancer. Lancet 370: 890-907, 2007.

45. Kurman RJ and Shih Ie M: Molecular pathogenesis and extraovarian origin of epithelial ovarian cancer-shifting the paradigm. Hum Pathol 42: 918-931, 2011.

46. Rajagopalan H, Nowak MA, Vogelstein B and Lengauer C: The significance of unstable chromosomes in colorectal cancer. Nat Rev Cancer 3: 695-701, 2003.

47. Lee BH, Roh S, Kim YI, Lee A and Kim SY: Difference of genome-wide copy number alterations between high-grade squamous intraepithelial lesions and squamous cell carcinomas of the uterine cervix. Korean J Pathol 46: 123-130, 2012.

48. Tornesello ML, Buonaguro L, Giorgi-Rossi $P$ and Buonaguro FM: Viral and cellular biomarkers in the diagnosis of cervical intraepithelial neoplasia and cancer. Biomed Res Int 2013: 519619, 2013.

49. Helms JA, Cordero D and Tapadia MD: New insights into craniofacial morphogenesis. Development 132: 851-861, 2005.

50. Diewert VM: Development of human craniofacial morphology during the late embryonic and early fetal periods. Am J Orthod 88: 64-76, 1985.

51. Moore KL and Persuad TVN (eds): The Developing Human: Clinicall Oriented Embryology. 8th edition. Saunders/Elsevier, Philadelphia, PA, 2007.

52. Löfdahl HE, Du J, Näsman A, Andersson E, Rubio CA, Lu Y, Ramqvist T, Dalianis T, Lagergren J and Dahlstrand H: Prevalence of human papillomavirus (HPV) in oesophageal squamous cell carcinoma in relation to anatomical site of the tumour. PLoS One 7: e46538, 2012.

53. Li R, Koch WM, Fakhry C and Gourin CG: Distinct epidemiologic characteristics of oral tongue cancer patients. Otolaryngol Head Neck Surg 148: 792-796, 2013. 